\title{
Subclinical Thyroid Dysfunction and Functional Capacity Among Elderly
}

\author{
Vanessa S. Virgini, ${ }^{1, *}$ Liselotte W. Wijsman, ${ }^{2,3, \star}{ }^{2}$ Nicolas Rodondi, ${ }^{1}$ Douglas C. Bauer, ${ }^{4}$ Patricia M. Kearney, ${ }^{5}$ \\ Jacobijn Gussekloo, ${ }^{6}$ Wendy P. J. den Elzen, ${ }^{6}$ J. Wouter Jukema, ${ }^{7}$ Rudi G.J. Westendorp, ${ }^{2}$ \\ Ian Ford, ${ }^{8}$ David J. Stott, ${ }^{9}$ and Simon P. Mooijaart, ${ }^{2,3,10}$ on behalf of the PROSPER Study Group
}

Background: Subclinical thyroid dysfunction is common among older people and has been associated with decreased functional capacity but with conflicting data. The aim of this study was to assess the association between subclinical thyroid dysfunction and functional capacity in an elderly population.

Methods: We included 5182 participants with a mean age of 75.2 years from the Prospective Study of Pravastatin in the Elderly at Risk (PROSPER). Self-reported functional capacity was assessed using the Barthel Index (BI) and the Instrumental Activities of Daily Living (IADL) scores at baseline and during follow-up. Participants with subclinical hyperthyroidism $(n=65)$ and subclinical hypothyroidism $(n=173)$ were compared to euthyroid participants $(n=4944)$. The association between persistent subclinical thyroid dysfunction and functional capacity and decline was also investigated.

Results: At baseline, compared to euthyroid participants (BI 19.73 \pm SE 0.06; IADL 13.52 \pm 0.02 ), there was no difference in functional capacity for participants with subclinical hyperthyroidism (BI 19.60 \pm 0.09 ; IADL $13.51 \pm 0.12, p>0.05$ ) or subclinical hypothyroidism (BI 19.82 \pm 0.06 ; IADL $13.55 \pm 0.08, p>0.05$ ). Over a mean 3.2year follow-up period, there was no association between thyroid function and annual decline of either BI or IADL $(p>0.05)$. No association was found between persistent subclinical thyroid dysfunction and functional capacity at baseline or during follow-up $(p>0.05)$. Results were similar after excluding participants with a maximum BI and/or IADL score at baseline.

Conclusion: Among well-functioning community-dwelling elderly, we found no evidence that subclinical thyroid dysfunction contributes to decreased functional capacity.

\section{Introduction}

$\mathbf{S}$ UBCLINICAL THYROID DYSFUNCTION is a common condition, particularly among older people (1-3). It is defined as a biochemical perturbation of thyrotropin (TSH) values with normal free T4 levels $(1,3,4)$, irrespective of the presence or absence of symptoms $(3,5,6)$. The prevalence of subclinical thyroid dysfunction increases with age, reaching up to $4 \%$ for subclinical hyperthyroidism (1-3) and up to $20 \%$ for subclinical hypothyroidism in subjects older than 65 years of age $(1,3,7)$.
Subclinical thyroid dysfunction has been associated with several adverse outcomes, such as cardiovascular disease (8$10)$, osteoporosis (1,11-13), and cognitive dysfunction $(6,14,15)$. Furthermore, subclinical thyroid dysfunction has also been associated with decreased functional capacity (16) and neuromuscular abnormalities (17), but data are conflicting (17-20), and reliable evidence on the association between subclinical thyroid dysfunction and functional capacity in an older population is lacking.

Both subclinical hyperthyroidism and subclinical hypothyroidism may progress to overt disease or revert to

\footnotetext{
${ }^{1}$ Department of General Internal Medicine, Inselspital, University Hospital of Bern, Bern, Switzerland.

Departments of ${ }^{2}$ Gerontology and Geriatrics, ${ }^{6}$ Public Health and Primary Care, and ${ }^{7}$ Cardiology, Leiden University Medical Center, Leiden, The Netherlands.

${ }^{3}$ Netherlands Consortium for Healthy Aging, Leiden, The Netherlands.

${ }^{4}$ Department of Internal Medicine, San Francisco University Medical Center, San Francisco, California.

${ }^{5}$ Department of Epidemiology and Public Health, University College Cork, Cork, Ireland.

${ }^{8}$ Robertson Centre, Institute of Health and Wellbeing; ${ }^{9}$ Institute of Cardiovascular and Medical Sciences; University of Glasgow, Glasgow, United Kingdom.

${ }^{10}$ Institute for Evidence-Based Medicine in Old Age, Leiden, The Netherlands.

*These two authors are co-first authors.
} 
euthyroidism in the course of months (21). Studies with repeated TSH measurements, which can identify persistent thyroid dysfunction, may be more strongly associated with specific endpoints than studies with a single measurement of TSH. To date, there are no data on the association between persistent subclinical thyroid dysfunction and functional capacity.

Therefore, we assessed the association between subclinical thyroid dysfunction and functional capacity in the Prospective Study of Pravastatin in the Elderly at Risk (PROSPER) (22). In more than 5000 participants, we investigated the association between thyroid status at baseline and persistent thyroid status after six months, and repeated assessments of functional capacity during a mean 3.2-year follow-up period.

\section{Methods}

\section{Subjects}

All subjects were participants of the PROSPER trial, designed to assess if pravastatin would reduce the risk of cardiovascular events in an elderly population with cardiovascular disease or at high risk of developing cardiovascular disease. Details on the study design have been previously described (23). A total of 5804 men and women aged 70-82 years with pre-existing cardiovascular disease (including coronary, cerebrovascular, or peripheral artery disease) or at risk to develop such a condition (current cigarette smoking, hypertension, known diabetes mellitus, or fasting blood glucose $>7 \mathrm{mmol} / \mathrm{L}$ ) were randomized to receive either pravastatin $40 \mathrm{mg}$ daily or placebo over a mean 3.2-year period in Scotland, Ireland, and the Netherlands. Participants with congestive heart failure (New York Heart Association III or IV), physical or mental inability to attend the clinic for the screening visit, or poor cognitive function (Mini Mental Score Examination $<24$ points) were excluded from the PROSPER trial.

From the initial trial population, we excluded participants with missing TSH and/or free T4 levels and with missing Barthel Index (BI) or Instrumental Activities of Daily Living (IADL) scores. Participants using antithyroid medication and/or thyroxine supplementation were also excluded. The trial protocol was approved by the Medical Ethic Committees of all involved centers, and all participants provided written informed consent.

\section{Thyroid function}

TSH was measured at baseline in all participants. Measurements were performed in three respective laboratory centers (Glasgow in the United Kingdom, Cork in Ireland, and Leiden in the Netherlands). Indications for additional measurements of free T4 were different between countries. In Scotland and Ireland, free T4 levels were measured when TSH was abnormal based upon specific cutoff levels of TSH (when TSH was $<0.45$ or $>10 \mathrm{mIU} / \mathrm{L}$ in Scotland, and $<0.3$ or $>5 \mathrm{mIU} / \mathrm{L}$ in Ireland), while they were measured in all participants in the Netherlands, independently of the TSH result.

TSH and free T4 levels were measured using state-of-theart immunoassays (third-generation assays with a functional sensitivity $\leq 0.05 \mathrm{mIU} / \mathrm{L}$ ). For both measurements, estimated inter- and intra-assay coefficients of variation were less than $5 \%$. Both TSH and free T4 levels were measured again at six months of follow-up in available frozen plasma samples of all participants, which were stored at the University of Glasgow. The same electrochemiluminescence immunodetection method on a Roche Elecsys 2010 (Burgess Hill, United Kingdom) was used. The limits of detection were $<0.005 \mathrm{mIU} / \mathrm{L}$ for TSH and $0.3 \mathrm{pmol} / \mathrm{L}$ for free T4 (reference range: 12 $22 \mathrm{pmol} / \mathrm{L}$ ). A reference range between 0.45 and $4.50 \mathrm{mIU} / \mathrm{L}$ derived from relevant literature was used for TSH $(4,9)$. The narrowest free T4 reference range (12-18 pmol/L) was chosen to take interlaboratory differences into account (24).

On the basis of previous publications $(4,25-28)$, we classified participants into three thyroid states groups. At baseline, subclinical hypothyroidism was defined as TSH levels $\geq 4.5 \mathrm{mIU} / \mathrm{L}$ with normal free T4 levels. Subclinical hyperthyroidism was defined as TSH levels $\leq 0.45 \mathrm{mIU} / \mathrm{L}$ with normal free T4 levels. Participants with normal TSH levels $(0.45-4.5 \mathrm{mIU} / \mathrm{L})$ were considered euthyroid. At six months, we used the same classification to define subclinical thyroid status. Participants with the same condition at baseline and after six months were defined as having persistent subclinical hypothyroidism, persistent subclinical hyperthyroidism, or persistent euthyroidism. Based on previous studies $(4,8,9,24,26,28)$ and expert reviews $(4,27)$, we further stratified our analyses for other TSH ranges (TSH $<0.1$, TSH 0.1-0.45, TSH 4.5-10, and TSH $>10 \mathrm{mIU} / \mathrm{L}$ ).

\section{Functional capacity}

Functional capacity was measured using two questionnaires: the BI and the IADL. Both questionnaires have previously been proven to be sensitive to detect changes in an elderly population $(29,30)$. The measurements were performed at baseline; after 9, 18, and 30 months; and at the end of the study, which varied between 36 and 42 months.

The BI is a common questionnaire used to assess self-care activities of daily living and level of dependence of an individual (31). The BI consists of 10 items, in which fecal and urinary continence, grooming, toilet use, feeding, transfers (e.g., from chair to bed), walking, dressing, climbing stairs, and bathing are scored. The maximum score of the BI is 20 points; a higher score represents higher independence and mobility, that is, higher functional capacity.

The IADL questionnaire also measures activities of daily living, but involves interaction with the physical and social environment (32), and is therefore questioning about more complex tasks compared to the BI. The questionnaire includes seven items, including housework, taking medication as prescribed, managing money, shopping for groceries or clothing, use of telephone or other form of communication, using technology, and transportation within the community. The maximum score of the IADL is 14 points; a higher score also means higher independence and mobility in both indoor and outdoor environment, that is, higher functional capacity.

\section{Statistical analyses}

Baseline characteristics are reported in three thyroid subgroups, according to thyroid status. $t$-Tests and chi-square tests were used to compare participants with subclinical thyroid dysfunction to euthyroid participants. We performed linear regression analyses to assess the cross-sectional association between subclinical thyroid status and functional capacity. Adjustments were made for age, sex, country, history 
of vascular disease, history of diabetes, history of hypertension, and current smoking.

Since treatment with pravastatin did not affect functional capacity (22), we combined data from both groups to investigate the association between subclinical thyroid dysfunction and functional decline. For this longitudinal association, we used linear mixed models, which included baseline thyroid status or persistent thyroid status, time (in years), and the interaction term between time and baseline thyroid status or persistent thyroid status. The dependent variable was the score on BI and IADL questionnaires. The change in functional capacity per year for each group was represented by the estimated value for annual change over time. Models were adjusted for age, sex, country, statin treatment, history of vascular disease, history of diabetes, history of hypertension, and current smoking.

Additionally, we further performed analyses in which we (i) investigated participants with suppressed or elevated TSH levels (TSH < 0.1 or TSH $>10$ mIU /L); (ii) included TSH levels as a continuous variable in our analyses; (iii) stratified the analyses by cardiovascular disease and risk factors to investigate their potential confounding effect; (iv) excluded participants with a maximum BI and/or IADL score at baseline; (v) stratified the longitudinal analyses by treatment group; and (vi) used a wider free T4 range, with $10.3-25.7 \mathrm{pmol} / \mathrm{L}$ considered normal according to relevant literature $(4,33)$. Finally, since we previously reported that subclinical hypothyroidism with TSH levels $>10 \mathrm{mIU} / \mathrm{L}$ was associated with a higher rate of heart failure in PROSPER (24), a decreased level of functional capacity among those participants is expected. Therefore, we further investigated whether excluding these participants from the analyses changed our results.
$p$-Values below 0.05 were considered statistically significant. All analyses were conducted using SPSS (v20.0; PASW Statistics Inc., Chicago, IL).

\section{Results}

\section{Baseline characteristics}

From the initial study population of 5804 participants, 8 individuals with missing TSH values, 303 with abnormal TSH and unknown free T4 values, 136 with overt thyroid disease, and 1 with missing BI and IADL scores were excluded (Fig. 1). Six participants taking antithyroid medication and 160 participants using thyroxine supplementation were excluded. The final sample of our study was therefore 5182 participants.

The mean age of the study population was 75.3 years (standard deviation [SD] 3.3 years; Table 1). A total of 65 participants had subclinical hyperthyroidism. In line with our expectation, this condition was more common in women $(73.8 \%)$ than in men. Subclinical hypothyroidism was found in 173 participants, and $64.2 \%$ were women. Groups were similar on most variables, except for body mass index (BMI) and hypertension. Subclinical hyperthyroidism was associated with lower BMI when compared to euthyroid participants (25.7vs. 26.8; $p=0.03$ ). The prevalence of hypertension was higher in participants with subclinical hypothyroidism compared to those with euthyroidism $(68.2 \%$ vs. $61.0 \% ; p=0.02)$.

\section{Baseline thyroid status and functional capacity}

At baseline, the overall mean BI and IADL scores were high (19.71 and 13.53 points respectively) with a range of 11-20 points for the BI and 4-14 points for the IADL (Table 2). The
FIG. 1. Flowchart of study participants. TSH, thyrotropin; FT4, free thyroxine; BI, Barthel Index; IADL, Instrumental Activities of Daily Living.

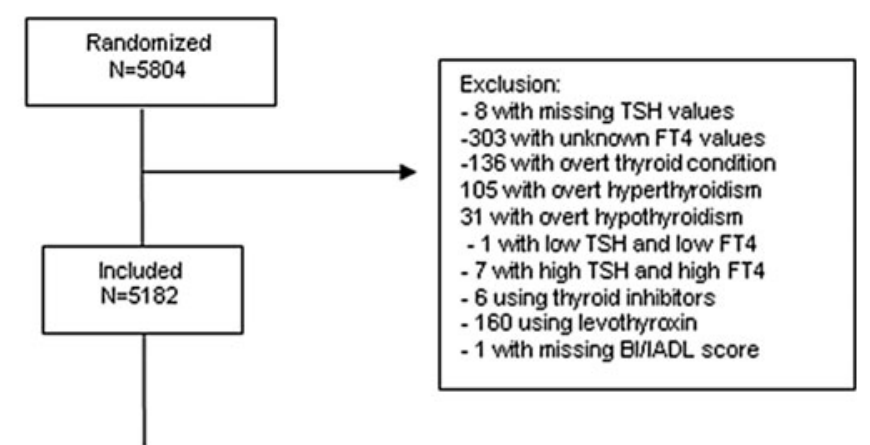

Thyroid status at baseline

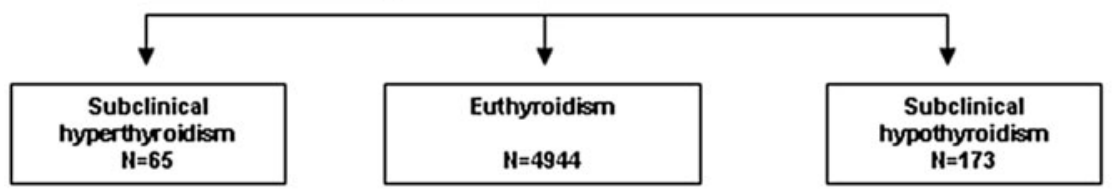

Persistent thyroid status

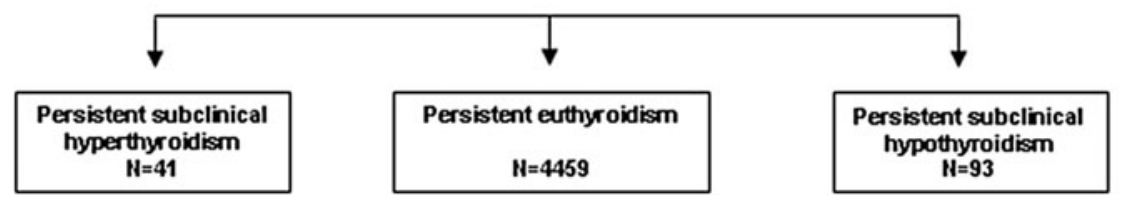


Table 1. Baseline Characteristics of Study Participants Depending on Thyroid Status

\begin{tabular}{|c|c|c|c|c|c|c|}
\hline & \multirow[b]{2}{*}{$\begin{array}{c}\text { All } \\
(\mathrm{N}=5182)\end{array}$} & \multicolumn{3}{|c|}{ Thyroid status } & \multicolumn{2}{|c|}{$\mathrm{p}$-Value for difference } \\
\hline & & $\begin{array}{c}\text { Subclinical } \\
\text { hyperthyroidism } \\
(\mathrm{n}=65)\end{array}$ & $\begin{array}{l}\text { Euthyroidism } \\
(\mathrm{n}=4944)\end{array}$ & $\begin{array}{c}\text { Subclinical } \\
\text { hypothyroidism } \\
(\mathrm{n}=173)\end{array}$ & $\begin{array}{c}\text { Subclinical } \\
\text { hyperthyroidism } \\
\text { vs. euthyroidism }\end{array}$ & $\begin{array}{c}\text { Subclinical } \\
\text { hypothyroidism } \\
\text { vs. euthyroidism }\end{array}$ \\
\hline \multicolumn{7}{|l|}{ Demographics } \\
\hline Female, $n(\%)$ & $2556(49.3 \%)$ & $48(73.8 \%)$ & $2397(48.5 \%)$ & $111(64.2 \%)$ & $<0.001$ & $<0.001$ \\
\hline Age (years), mean $\pm S D$ & $75.3 \pm 3.3$ & $75.3 \pm 0.4$ & $75.3 \pm 0.1$ & $75.6 \pm 0.3$ & 0.91 & 0.20 \\
\hline $\begin{array}{l}\text { Education (age left } \\
\text { school), mean } \pm \text { SD }\end{array}$ & $15.1 \pm 2.1$ & $15.3 \pm 0.3$ & $15.1 \pm 0.0$ & $15.2 \pm 0.2$ & 0.56 & 0.84 \\
\hline \multicolumn{7}{|l|}{ Biometrics, mean $\pm S E^{a}$} \\
\hline Weight $(\mathrm{kg})$ & $73.5 \pm 0.2$ & $71.7 \pm 1.5$ & $73.5 \pm 0.2$ & $75.2 \pm 0.9$ & 0.26 & 0.07 \\
\hline Height $(\mathrm{cm})$ & $165.5 \pm 0.1$ & $166.6 \pm 0.8$ & $165.4 \pm 0.1$ & $166.6 \pm 0.5$ & 0.15 & 0.02 \\
\hline $\operatorname{BMI}\left(\mathrm{kg} / \mathrm{m}^{2}\right)$ & $26.8 \pm 0.1$ & $25.7 \pm 0.5$ & $26.8 \pm 0.1$ & $27.0 \pm 0.3$ & 0.03 & 0.48 \\
\hline SBP (mmHg) & $154.7 \pm 0.3$ & $153.8 \pm 2.7$ & $154.6 \pm 0.3$ & $157.0 \pm 1.7$ & 0.77 & 0.16 \\
\hline $\mathrm{DBP}(\mathrm{mmHg})$ & $83.9 \pm 0.2$ & $82.6 \pm 1.4$ & $83.9 \pm 0.2$ & $84.4 \pm 0.9$ & 0.38 & 0.53 \\
\hline \multicolumn{7}{|c|}{ Cardiovascular risk factors, $n(\%)$} \\
\hline Current smoker & $1422(27.4 \%)$ & $12(18.5 \%)$ & $1371(27.7 \%)$ & $39(22.5 \%)$ & 0.14 & 0.08 \\
\hline History of diabetes & $561(10.8 \%)$ & $10(15.4 \%)$ & $526(10.6 \%)$ & $25(14.5 \%)$ & 0.25 & 0.20 \\
\hline History of hypertension & $3173(61.2 \%)$ & $38(58.5 \%)$ & $3017(61.0 \%)$ & $118(68.2 \%)$ & 0.61 & 0.02 \\
\hline $\begin{array}{l}\text { History of vascular } \\
\text { disease }\end{array}$ & $2293(44.2 \%)$ & $26(40.0 \%)$ & $2190(44.3 \%)$ & 77 (44.5\%) & 0.51 & 0.84 \\
\hline History of TIA/stroke & $585(11.3 \%)$ & $6(9.2)$ & $556(11.2 \%)$ & $23(13.3 \%)$ & 0.56 & 0.94 \\
\hline
\end{tabular}

adjusted for age and sex.

$N$, number; SD, standard deviation; SE, standard error; BMI, body mass index; SBP, systolic blood pressure; DBP, diastolic blood pressure; TIA, transient ischemic attack.

mean score on BI and IADL did not differ among participants with subclinical hyperthyroidism and subclinical hypothyroidism compared to euthyroid participants $(p>0.05)$. Although a significant decrease in functional capacity over the 3.2-year follow-up time was observed for both BI and IADL $(-0.09$ and -0.16 points per year respectively; $p<0.001)$, there was no difference in annual decline of BI or IADL when comparing participants with subclinical thyroid dysfunction to euthyroid participants $(p>0.05)$. The results did not materially change after (i) investigation of potential differences within TSH subgroups (TSH $<0.1$ and TSH $>10 \mathrm{mIU} / \mathrm{L}$ ); (ii) analysis of TSH as a continuous variable; (iii) stratification by presence or absence of cardiovascular disease at baseline; (iv) exclusion of participants with a maximal BI and/or IADL score at baseline; (v) stratification by treatment group; and (vi) using a wider free T4 range (data not shown). Furthermore, we found that participants with incident heart failure hospi- talization $(n=235)$ had a significant decrease in both BI and IADL over the 3.2-year follow-up time $(-0.31$ and -0.51 points per year respectively; $p<0.001$ ), but excluding these participants did not change the results.

\section{Persistent thyroid status and functional capacity}

Among the 65 participants with subclinical hyperthyroidism at baseline, 41 still had subclinical hyperthyroidism after six months and were defined as having persistent subclinical hyperthyroidism. Among the 173 participants with subclinical hypothyroidism at baseline, 93 had subclinical hypothyroidism at six months and were defined as having persistent subclinical hypothyroidism. After exclusion of participants with changing thyroid status, there were no differences in functional capacity between groups with persistent thyroid status at six months (Table $3 ; p>0.05$ ). No association between

Table 2. Functional Capacity and Decline Depending on Thyroid Status at Baseline

\begin{tabular}{|c|c|c|c|c|c|c|}
\hline \multirow[b]{2}{*}{$\begin{array}{l}\text { Functional capacity, } \\
\text { mean } \pm S E\end{array}$} & \multirow[b]{2}{*}{$\begin{array}{c}\text { All } \\
(\mathrm{N}=5182)\end{array}$} & \multicolumn{3}{|c|}{ Thyroid status } & \multicolumn{2}{|c|}{$\mathrm{p}$-Value for difference } \\
\hline & & $\begin{array}{c}\text { Subclinical } \\
\text { hyperthyroidism } \\
(\mathrm{n}=65)\end{array}$ & $\begin{array}{l}\text { Euthyroidism } \\
(\mathrm{n}=4944)\end{array}$ & $\begin{array}{c}\text { Subclinical } \\
\text { hypothyroidism } \\
(\mathrm{n}=173)\end{array}$ & $\begin{array}{c}\text { Subclinical } \\
\text { hyperthyroidism } \\
\text { vs. euthyroidism }\end{array}$ & $\begin{array}{c}\text { Subclinical } \\
\text { hypothyroidism } \\
\text { vs. euthyroidism }\end{array}$ \\
\hline Barthel Index, range & 11-20 & 15-20 & $11-20$ & 15-20 & & \\
\hline Baseline score & $19.71 \pm 0.04$ & $19.60 \pm 0.09$ & $19.73 \pm 0.06$ & $19.82 \pm 0.06$ & 0.147 & 0.103 \\
\hline Annual change & $-0.09 \pm 0.00$ & $-0.08 \pm 0.03$ & $-0.09 \pm 0.00$ & $-0.09 \pm 0.02$ & 0.859 & 0.952 \\
\hline IADL, range & 4-14 & 10-14 & 4-14 & 7-14 & & \\
\hline Baseline score & $13.53 \pm 0.05$ & $13.51 \pm 0.12$ & $13.52 \pm 0.02$ & $13.55 \pm 0.08$ & 0.910 & 0.721 \\
\hline Annual change & $-0.16 \pm 0.01$ & $-0.23 \pm 0.05$ & $-0.16 \pm 0.01$ & $-0.14 \pm 0.03$ & 0.144 & 0.641 \\
\hline
\end{tabular}

Data represent mean \pm SE. Adjusted for age, sex, country, history of vascular diseases, history of hypertension, history of diabetes mellitus, current smoking, and additionally for statin treatment in the longitudinal analyses.

IADL, Instrumental Activities for Daily Living. 
Table 3. Functional Capacity and Decline Depending on Persistent Thyroid Status

\begin{tabular}{|c|c|c|c|c|c|c|}
\hline \multirow[b]{2}{*}{$\begin{array}{l}\text { Functional capacity, } \\
\text { mean } \pm S E\end{array}$} & \multirow[b]{2}{*}{$\begin{array}{c}\text { All } \\
(\mathrm{N}=4593)\end{array}$} & \multicolumn{3}{|c|}{ Persistent thyroid status } & \multicolumn{2}{|c|}{$\mathrm{p}$-Value for difference } \\
\hline & & $\begin{array}{c}\text { Subclinical } \\
\text { hyperthyroidism } \\
(\mathrm{n}=41)\end{array}$ & $\begin{array}{l}\text { Euthyroidism } \\
\quad(\mathrm{n}=4459)\end{array}$ & $\begin{array}{c}\text { Subclinical } \\
\text { hypothyroidism } \\
(\mathrm{n}=93)\end{array}$ & $\begin{array}{c}\text { Subclinical } \\
\text { hyperthyroidism } \\
\text { ws. euthyroidism }\end{array}$ & $\begin{array}{c}\text { Subclinical } \\
\text { hypothyroidism } \\
\text { vs. euthyroidism }\end{array}$ \\
\hline Barthel Index, range & $11-20$ & 15-20 & 11-20 & 18-20 & & \\
\hline Baseline score & $19.73 \pm 0.05$ & $19.59 \pm 0.11$ & $19.74 \pm 0.02$ & $19.85 \pm 0.07$ & 0.161 & 0.151 \\
\hline Annual change & $-0.08 \pm 0.00$ & $-0.04 \pm 0.04$ & $-0.08 \pm 0.0$ & $-0.09 \pm 0.03$ & 0.486 & 0.807 \\
\hline IADL, range & 4-14 & 10-14 & 4-14 & 7-14 & & \\
\hline Baseline score & $13.52 \pm 0.06$ & $13.43 \pm 0.15$ & $13.53 \pm 0.03$ & $13.60 \pm 0.10$ & 0.477 & 0.527 \\
\hline Annual change & $-0.15 \pm 0.01$ & $-0.19 \pm 0.06$ & $-0.15 \pm 0.01$ & $-0.12 \pm 0.04$ & 0.536 & 0.444 \\
\hline
\end{tabular}

Data represent mean \pm SE. Adjusted for age, sex, country, history of vascular diseases, history of hypertension, history of diabetes mellitus, current smoking and additionally for statin treatment in the longitudinal analyses.

persistent thyroid status and functional decline over time was observed $(p>0.05)$.

\section{Discussion}

In this large prospective cohort study of more than 5000 older persons, including an analysis with persistent subclinical thyroid dysfunction, we found no consistent association between subclinical thyroid dysfunction and self-reported functional capacity or decline in old age.

Previously, few studies evaluated the relationship between subclinical thyroid dysfunction and functional capacity, with conflicting results. A cross-sectional study that included 42 participants with subclinical hypothyroidism found no association with functional capacity as measured by the Bruce treadmill (17). Similarly, the Leiden 85-Plus Study, a population-based study, showed that subclinical thyroid dysfunction was not associated with functional capacity in 558 participants from the age of 85 years onwards (18). Simonsick et al. showed that people between 70 and 79 years of age did not have more frequent mobility problems (20). In this study, individuals with a mild elevation in TSH levels $(4.5-7 \mathrm{mIU} / \mathrm{L})$ had a faster mean usual and rapid gait speed and better cardiorespiratory fitness and reported walking ease. Portella et al. reported that subclinical hyperthyroidism was not associated with changes in exercise performance in young female adults (19). This experimental study included only 14 participants with well-differentiated thyroid carcinoma on suppressive levothyroxine therapy leading to subclinical hypothyroidism, and assessed exercise capacity by using the treadmill cardiopulmonary test. Furthermore, a randomized study demonstrated that exercise performance was improved in individuals with subclinical hypothyroidism treated with levothyroxine after six months of TSH normalization (16).

According to several hypotheses, we expected to find an association between subclinical thyroid status and functional capacity. First, as subclinical thyroid dysfunction has been associated with cardiovascular disease (8-10), we hypothesized a decline in functional capacity in those with subclinical thyroid status due to a higher rate of cardiovascular events, such as stroke or myocardial infarction (24). Second, literature shows that individuals with both subclinical and overt thyroid conditions have more frequent musculoskeletal symptoms. An experimental study demonstrated that higher free
T4 concentrations were associated with decreased physical performance and muscle strength, independently of TSH levels (34). A cross-sectional study including 137 participants showed that Dupuytren's contracture, limited joint mobility, and carpal tunnel syndrome were significantly more common among middle-aged subjects with hypothyroidism (35). Moreover, subclinical hyperthyroidism and overt hyperthyroidism have also been associated with increased risk of osteoporosis $(1,11-13)$, which could also contribute to impaired functional capacity. Therefore, we expected that similar manifestations could be observed in subclinical thyroid states, leading to decline of functional capacity. Finally, as subclinical thyroid dysfunction has been linked to adverse cognitive outcomes $(6,14,15)$, we assumed that functional capacity could be impaired in individuals with subclinical thyroid dysfunction due to additional cognitive decline.

The fact that we did not find any association between subclinical thyroid dysfunction and changes in functional capacity could be explained by two main reasons. The first is that the hypothesized biological relation does not exist. So far, only one study investigated muscle metabolism and exercise tolerance impairments as possible biological mechanisms involved in subclinical hypothyroidism (36). Muscle metabolism has also been suggested to be impaired in Hashimoto's hypothyroid myopathy (37). The few other positive studies on the association between subclinical thyroid dysfunction and functional capacity did not clearly report which biological mechanisms could be involved $(16,17)$. Second, the participants in the PROSPER study were excluded at baseline if they had poor cognitive function (Mini Mental Score Examination $<24 / 30$ points) or if they were physically or mentally unable to attend the clinic for the screening visit (23). Therefore, the population in this study excluded elderly with functional and cognitive impairment, potentially leading to reduced power to detect changes in functional capacity. However, we did observe a significant decline in functional capacity among all participants $(n=5182)$ and in a small subgroup analysis $(n=235)$, suggesting that our measurements were sensitive enough to detect functional decline. Although the rate of spontaneous normalization of TSH levels in subclinical thyroid disorders can be as high as $65 \%$, studies evaluating persistent subclinical thyroid dysfunction are rare $(38,39)$. The fact that we have data on persistence of subclinical thyroid dysfunction, which is the most robust reflection of subclinical 
thyroid status and a limitation of several previous studies, together with repeated measurements of functional capacity increased our power to detect a potential association and a decline in functional capacity over time. Moreover, the large sample size of our study and the overall high prevalence of subclinical thyroid dysfunction increased the power to detect an association between subclinical thyroid conditions and functional capacity.

There are several limitations in our study. First, the studied population had a good functional capacity at baseline. Therefore, our findings are only generalizable to a high functioning population. Second, the 3.2-year follow-up period could have limited the power to detect changes in functional capacity among our population. A longer follow-up period might be needed to find changes in functional capacity. Furthermore, only two self-reporting questionnaires to assess functional capacity were used, which might be insensible to detect changes. However, it has recently been shown that subclinical thyroid dysfunction was not associated with cognitive performance or decline in the present population (33). Although cognitive decline has been reported for many determinants in the studied population (40-42), the absence of such association between subclinical thyroid dysfunction and cognitive decline further strengthens the findings of our analyses, which shows no association with functional capacity or decline. Finally, as indications for free T4 measurements differed for each country, this could have resulted in some differences between the participants in Scotland, Ireland, or the Netherlands. However, free T4 was measured in all participants with TSH $>10 \mathrm{mIU} / \mathrm{L}$, a group in which we also did not find a significant association.

In conclusion, there is no evidence to support a relationship between subclinical thyroid dysfunction and functional capacity in a large population of well-functioning communitydwelling older people.

\section{Acknowledgments}

This study was supported by a grant from the Swiss National Science Foundation (SNSF 320030-138267) and partially supported by a grant from the Swiss Heart Foundation (both to Prof. N. Rodondi). The original PROSPER trial was supported by an unrestricted, investigator-initiated grant from Bristol-Myers Squibb.

\section{Author Disclosure Statement}

No competing financial interests exist. The funders had no role in analysis and interpretation of the data nor in writing and publishing of the manuscript. There are no patents, products in development, or marketed products to declare.

\section{References}

1. Cooper DS, Biondi B 2012 Subclinical thyroid disease. Lancet 379:1142-1154.

2. Hollowell JG, Staehling NW, Flanders WD, Hannon WH, Gunter EW, Spencer CA, Braverman LE 2002 Serum TSH, $\mathrm{T}(4)$, and thyroid antibodies in the United States population (1988 to 1994): National Health and Nutrition Examination Survey (NHANES III). J Clin Endocrinol Metab 87:489-499.

3. Razvi S, Weaver JU, Pearce SH 2010 Subclinical thyroid disorders: significance and clinical impact. J Clin Pathol 63:379-386.
4. Surks MI, Ortiz E, Daniels GH, Sawin CT, Col NF, Cobin RH, Franklyn JA, Hershman JM, Burman KD, Denke MA, Gorman C, Cooper RS, Weissman NJ 2004 Subclinical thyroid disease: scientific review and guidelines for diagnosis and management. JAMA 291:228-238.

5. Biondi B 2008 Should we treat all subjects with subclinical thyroid disease the same way? Eur J Endocrinol 159:343-345.

6. Valenti G, Fabbo A 1996 Subclinical hypothyroidism in the elderly. Arch Gerontol Geriatr 22:585-592.

7. Bemben DA, Winn P, Hamm RM, Morgan L, Davis A, Barton E 1994 Thyroid disease in the elderly. Part 1. Prevalence of undiagnosed hypothyroidism. J Fam Pract 38: 577-582.

8. Collet TH, Gussekloo J, Bauer DC, den Elzen WP, Cappola AR, Balmer P, Iervasi G, Asvold BO, Sgarbi JA, Volzke H, Gencer B, Maciel RM, Molinaro S, Bremner A, Luben RN, Maisonneuve $\mathrm{P}$, Cornuz J, Newman AB, Khaw KT, Westendorp RG, Franklyn JA, Vittinghoff E, Walsh JP, Rodondi N 2012 Subclinical hyperthyroidism and the risk of coronary heart disease and mortality. Arch Intern Med 172:799-809.

9. Rodondi N, den Elzen WP, Bauer DC, Cappola AR, Razvi S, Walsh JP, Asvold BO, Iervasi G, Imaizumi M, Collet TH, Bremner A, Maisonneuve P, Sgarbi JA, Khaw KT, Vanderpump MP, Newman AB, Cornuz J, Franklyn JA, Westendorp RG, Vittinghoff E, Gussekloo J 2010 Subclinical hypothyroidism and the risk of coronary heart disease and mortality. JAMA 304:1365-1374.

10. Sawin CT 2002 Subclinical hyperthyroidism and atrial fibrillation. Thyroid 12:501-503.

11. Bauer DC, Ettinger B, Nevitt MC, Stone KL 2001 Risk for fracture in women with low serum levels of thyroidstimulating hormone. Ann Intern Med 134:561-568.

12. Biondi B 2012 Natural history, diagnosis and management of subclinical thyroid dysfunction. Best Pract Res Clin Endocrinol Metab 26:431-446.

13. Lee JS, Buzkova P, Fink HA, Vu J, Carbone L, Chen Z, Cauley J, Bauer DC, Cappola AR, Robbins J 2010 Subclinical thyroid dysfunction and incident hip fracture in older adults. Arch Intern Med 170:1876-1883.

14. Begin ME, Langlois MF, Lorrain D, Cunnane SC 2008 Thyroid function and cognition during aging. Curr Gerontol Geriatr Res 474868.

15. Ceresini G, Lauretani F, Maggio M, Ceda GP, Morganti S, Usberti E, Chezzi C, Valcavi R, Bandinelli S, Guralnik JM, Cappola AR, Valenti G, Ferrucci L 2009 Thyroid function abnormalities and cognitive impairment in elderly people: results of the Invecchiare in Chianti study. J Am Geriatr Soc 57:89-93.

16. Mainenti MR, Vigario PS, Teixeira PF, Maia MD, Oliveira FP, Vaisman M 2009 Effect of levothyroxine replacement on exercise performance in subclinical hypothyroidism. J Endocrinol Invest 32:470-473.

17. Reuters VS, Teixeira PF, Vigario PS, Almeida CP, Buescu A, Ferreira MM, de Castro CL, Gold J, Vaisman M 2009 Functional capacity and muscular abnormalities in subclinical hypothyroidism. Am J Med Sci 338:259-263.

18. Gussekloo J, van Exel E, de Craen AJ, Meinders AE, Frolich M, Westendorp RG 2004 Thyroid status, disability and cognitive function, and survival in old age. JAMA 292:2591-2599.

19. Portella RB, Silva JL, Wagman MB, de Oliveira FP, Buescu A, Vaisman M 2006 Exercise performance in young and middle-aged female patients with subclinical hyperthyroidism. Thyroid 16:731-735. 
20. Simonsick EM, Newman AB, Ferrucci L, Satterfield S, Harris TB, Rodondi N, Bauer DC 2009 Subclinical hypothyroidism and functional mobility in older adults. Arch Intern Med 169:2011-2017.

21. Jones DD, May KE, Geraci SA 2010 Subclinical thyroid disease. Am J Med 123:502-504.

22. Shepherd J, Blauw GJ, Murphy MB, Bollen EL, Buckley BM, Cobbe SM, Ford I, Gaw A, Hyland M, Jukema JW, Kamper AM, MacFarlane PW, Meinders AE, Norrie J, Packard CJ, Perry IJ, Stott DJ, Sweeney BJ, Twomey C, Westendorp RG 2002 Pravastatin in elderly individuals at risk of vascular disease (PROSPER): a randomised controlled trial. Lancet 360:1623-1630.

23. Shepherd J, Blauw GJ, Murphy MB, Cobbe SM, Bollen EL, Buckley BM, Ford I, Jukema JW, Hyland M, Gaw A, Lagaay AM, Perry IJ, Macfarlane PW, Meinders AE, Sweeney BJ, Packard CJ, Westendorp RG, Twomey C, Stott DJ 1999 The design of a Prospective Study of Pravastatin in the Elderly at Risk (PROSPER). PROSPER Study Group. PROspective Study of Pravastatin in the Elderly at Risk. Am J Cardiol 84:1192-1197.

24. Nanchen D, Gussekloo J, Westendorp RG, Stott DJ, Jukema JW, Trompet S, Ford I, Welsh P, Sattar N, Macfarlane PW, Mooijaart SP, Rodondi N, de Craen AJ 2012 Subclinical thyroid dysfunction and the risk of heart failure in older persons at high cardiovascular risk. J Clin Endocrinol Metab 97:852-861.

25. Cappola AR, Fried LP, Arnold AM, Danese MD, Kuller LH, Burke GL, Tracy RP, Ladenson PW 2006 Thyroid status, cardiovascular risk, and mortality in older adults. JAMA 295:1033-1041.

26. Gencer B, Collet TH, Virgini V, Bauer DC, Gussekloo J, Cappola AR, Nanchen D, den Elzen WP, Balmer P, Luben RN, Iacoviello $M$, Triggiani $V$, Cornuz J, Newman AB, Khaw KT, Jukema JW, Westendorp RG, Vittinghoff E, Aujesky D, Rodondi N 2012 Subclinical thyroid dysfunction and the risk of heart failure events: an individual participant data analysis from 6 prospective cohorts. Circulation 126:1040-1049.

27. Helfand M 2004 Screening for subclinical thyroid dysfunction in nonpregnant adults: a summary of the evidence for the U.S. Preventive Services Task Force. Ann Intern Med 140:128-141.

28. Rodondi N, Bauer DC, Cappola AR, Cornuz J, Robbins J, Fried LP, Ladenson PW, Vittinghoff E, Gottdiener JS, Newman AB 2008 Subclinical thyroid dysfunction, cardiac function, and the risk of heart failure. The Cardiovascular Health study. J Am Coll Cardiol 52:1152-1159.

29. Kwiatkowski TG, Libman RB, Frankel M, Tilley BC, Morgenstern LB, Lu M, Broderick JP, Lewandowski CA, Marler JR, Levine SR, Brott T 1999 Effects of tissue plasminogen activator for acute ischemic stroke at one year. National Institute of Neurological Disorders and Stroke Recombinant Tissue Plasminogen Activator Stroke Study Group. N Engl J Med 340:1781-1787.

30. Willis SL, Tennstedt SL, Marsiske M, Ball K, Elias J, Koepke KM, Morris JN, Rebok GW, Unverzagt FW, Stoddard AM, Wright E 2006 Long-term effects of cognitive training on everyday functional outcomes in older adults. JAMA 296:2805-2814.

31. Mahoney FI, Barthel DW 1965 Functional evaluation: the Barthel Index. Md State Med J 14:61-65.
32. Lawton MP 1971 The functional assessment of elderly people. J Am Geriatr Soc 19:465-481.

33. Wijsman LW, de Craen AJ, Trompet S, Gussekloo J, Stott DJ, Rodondi N, Welsh P, Jukema JW, Westendorp RG, Mooijaart SP 2013 Subclinical thyroid dysfunction and cognitive decline in old age. PLoS One 8:e59199.

34. van den Beld AW, Visser TJ, Feelders RA, Grobbee DE, Lamberts SW 2005 Thyroid hormone concentrations, disease, physical function, and mortality in elderly men. J Clin Endocrinol Metab 90:6403-6409.

35. Cakir M, Samanci N, Balci N, Balci MK 2003 Musculoskeletal manifestations in patients with thyroid disease. Clin Endocrinol (Oxf) 59:162-167.

36. Caraccio N, Natali A, Sironi A, Baldi S, Frascerra S, Dardano A, Monzani F, Ferrannini E 2005 Muscle metabolism and exercise tolerance in subclinical hypothyroidism: a controlled trial of levothyroxine. J Clin Endocrinol Metab 90: 4057-4062.

37. Siciliano G, Monzani F, Manca ML, Tessa A, Caraccio N, Tozzi G, Piemonte F, Mancuso M, Santorelli FM, Ferrannini E, Murri L 2002 Human mitochondrial transcription factor A reduction and mitochondrial dysfunction in Hashimoto's hypothyroid myopathy. Mol Med 8:326-333.

38. Diez JJ, Iglesias P, Burman KD 2005 Spontaneous normalization of thyrotropin concentrations in patients with subclinical hypothyroidism. J Clin Endocrinol Metab 90: 4124-4127.

39. Meyerovitch J, Rotman-Pikielny P, Sherf M, Battat E, Levy Y, Surks MI 2007 Serum thyrotropin measurements in the community: five-year follow-up in a large network of primary care physicians. Arch Intern Med 167:1533-1538.

40. Mooijaart SP, Sattar N, Trompet S, Polisecki E, de Craen AJ, Schaefer EJ, Jahn SE, van HT, Welsh P, Ford I, Stott DJ, Westendorp RG 2011 C-reactive protein and genetic variants and cognitive decline in old age: the PROSPER study. PLoS One 6:e23890.

41. Packard CJ, Westendorp RG, Stott DJ, Caslake MJ, Murray HM, Shepherd J, Blauw GJ, Murphy MB, Bollen EL, Buckley BM, Cobbe SM, Ford I, Gaw A, Hyland M, Jukema JW, Kamper AM, Macfarlane PW, Jolles J, Perry IJ, Sweeney BJ, Twomey C 2007 Association between apolipoprotein E4 and cognitive decline in elderly adults. J Am Geriatr Soc 55:17771785.

42. Trompet S, de Craen AJ, Slagboom P, Shepherd J, Blauw GJ, Murphy MB, Bollen EL, Buckley BM, Ford I, Gaw A, Macfarlane PW, Packard CJ, Stott DJ, Jukema JW, Westendorp RG 2008 Genetic variation in the interleukin-1 betaconverting enzyme associates with cognitive function. The PROSPER study. Brain 131:1069-1077.

Address correspondence to: Simon P. Mooijaart, MD, PhD Department of Gerontology and Geriatrics Leiden University Medical Center

PO Box 9600 2300RC Leiden The Netherlands

E-mail: s.p.mooijaart@lumc.nl 